\title{
Case Study on the Rainwater Utilization Potentiality in Urban Area
}

\section{CHEN Shaoying, a , GAO Shipei, b, ZHU Zhenrong ${ }^{2, ~ c}$, PAN Yihui ${ }^{1,}$, CHEN Feng $^{1, e}$, BAO Jianteng ${ }^{3, f}$}

\author{
${ }^{1}$ Jiangsu Institute of Water Resources and Hydropower Research, China \\ ${ }^{2}$ Water Resources Department of Jiangsu Province \\ ${ }^{3}$ Flood Control and Drought Relief Headquarter Office of Jiangsu Province \\ ashaoying1020@163.com, b54400744@qq.com,'szr03@163.com, d160569451@qq.com, \\ e470966083@qq.com, ${ }^{f 1136428235 @ q q . c o m ~}$
}

\begin{abstract}
Keywords: rainwater utilization potentiality, sunken lawn, permeable brick, storage tank Abstract. Based on the newly developed concept of the rainwater utilization potentiality in urban area (RUPUA), RUPUA at the research site including the Beijing Olympic Park is estimated as 2,230,000 $\mathrm{m} 3$. Three measures were taken for increasing the rainwater utilization: sunken lawns, permeable bricks and water storage tanks. Their influences on the runoff change were discussed and different cases of rainwater utilization measures were researched. When all three measures were taken as designed, average annual rainwater utilization at the research site would be $414,000 \mathrm{~m} 3$, which is about $18.6 \%$ of the total potentiality.
\end{abstract}

\section{Definition of the rainwater utilization potentiality in urban area}

By now, there is no unanimous and exact definition on the rainwater utilization potentiality in urban area (RUPUA). Objectively, water resources in an area or a river basin come from the rainfall. According to the China Water Resources Assessment Guide, water resources assessments contain the assessment of the rainfall, surface water, groundwater and the total water resources. The rainwater utilization starts from the rainwater collection and using. Now the concept expands to the rainfall infiltration increasing and flood control. There are several concepts related to the rainwater utilization.

Theoretical value of the rainwater utilization potentiality. It refers to the total rainfall that theoretically can be used, and it equals to the multi-year average annual rainfall.

Actual value of rainwater utilization quantity. It refers to the sum of the rainwater that had been practically collected and used after the rainfall, it is related to the measures and facilities of the rainwater utilization.

The development of the urban area can't change the local rainfall, but because the construction of the buildings, roads and other facilities that changed the underlying surface, the rule of the runoff production will be changed. It is clear that development of the urban area can increase the surface runoff, these increased runoff can be further used if there are any rainwater utilization measures or facilities.

Rainwater utilization potentiality in urban area (RUPUA). This concept is used to assess the potentiality that the rainwater can be used after the development of the urban area. It is defined as the difference between the runoff after the development of the urban area and before the development of the urban area. It can be described as:

$$
W=1000 P\left(\alpha_{1}-\alpha_{2}\right) F \text {. }
$$

Where, 1000 is the unit conversion factor; $W$ is the rainwater utilization potentiality in urban area (RUPUA), $\mathrm{m}^{3} ; P$ is the multi-year average annual rainfall, $\mathrm{mm} ; \alpha_{1}$ is the runoff coefficient after the development of the urban area but without rainwater utilization measures. $\alpha_{2}$ is the runoff coefficient before the development of the urban area. Both runoff coefficients should be assessed based on the multi-year average annual rainfall. $F$ is the area of the assessed site, $\mathrm{km}^{2}$. 


\section{Research site description}

In this research, place around the Beijing Olympic Park was chosen as an example to research its rainwater utilization potentiality and compare the effect of the different rainwater use measures. The park is located at the north of the city and lies on the central axis of the city. The total area of the park is 1,135 hectares, it is basically composed by three parts: the northern part is a forest park with the area of 680 hectares, in the middle is the Olympic Sports Center with the area of 315 hectares, and at the southern part is the National Olympic Sports Center with the area of 114 hectares, as shown at the center of Fig. 1.

The research site is located at the south side of the Xindiancun Road within the dashed line in Fig. 1. Its area is 968 hectares. The landuse types of the research site are shown in Fig. 2, there are five types of the landuse including roads (0), construction area (1), green space (2), lake (3) and square (4). From the statistical data, it is known that the proportion of the impervious area is $79.0 \%$.

\section{Rainwater utilization potentiality of the Olympic Park}

\section{Runoff coefficient after development}

Based on the above definition of the rainwater utilization potentiality in urban area, the runoff coefficient is the most important parameter. If two runoff coefficients are available, then the potentiality can be simply calculated using Equation (1).

The calculation of the runoff coefficient after the development of the Olympic Park is

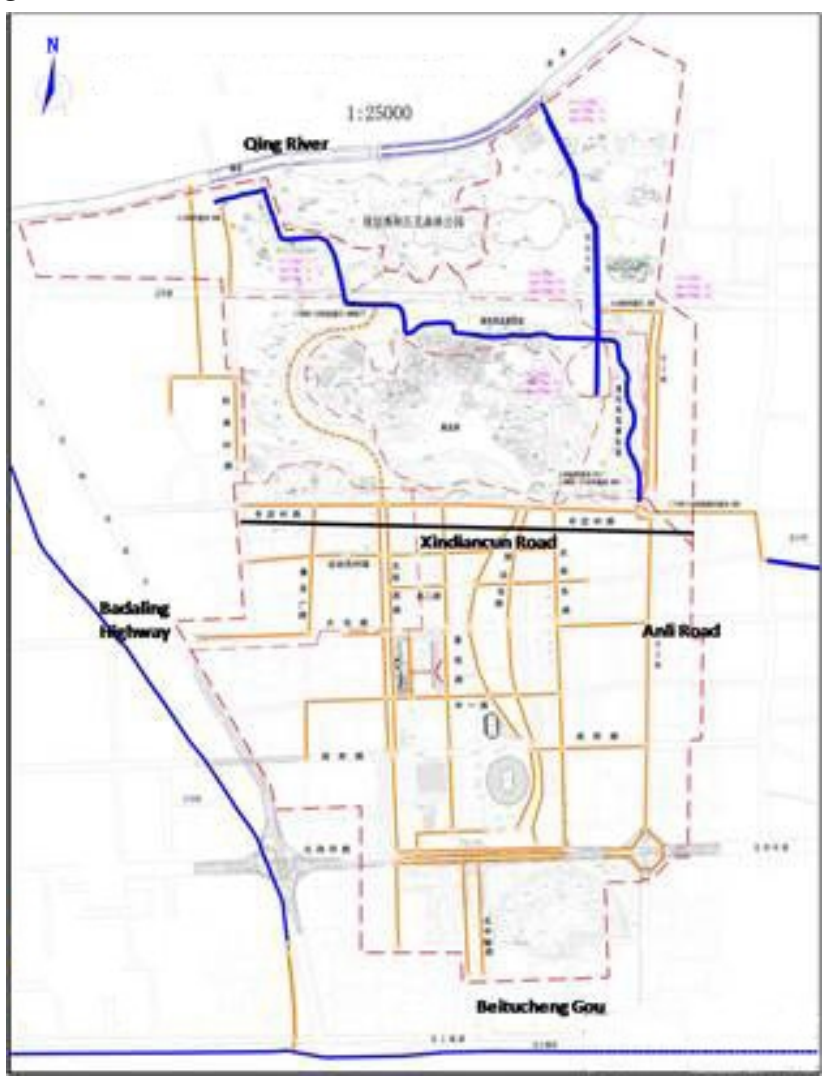

Fig. 1 The sketch of the research site

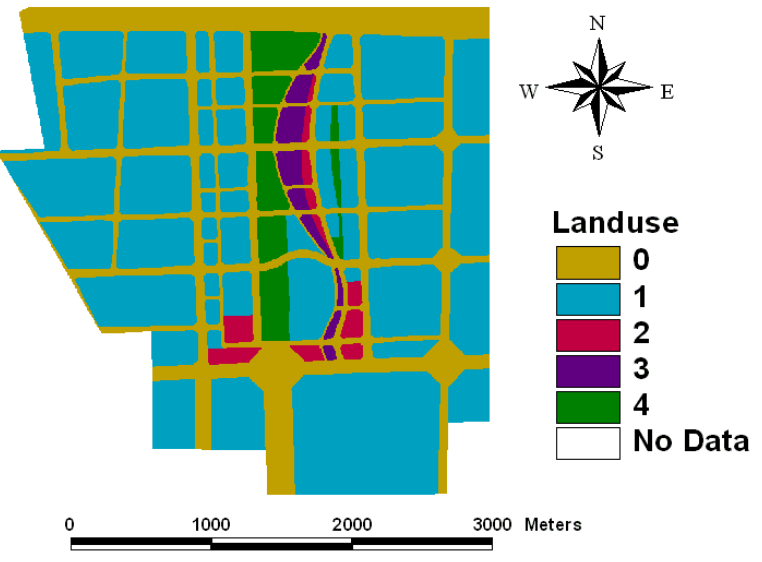

Fig. 2 Landuse types of the research site conducted using the HYrunoff, which was developed by the institute of hydrology and water resources at Tsinghua University based on the HYDRUS.

HYDRUS, which is developed at the U.S. Salinity Laboratory, is a Galerkin linear finite element program for simulating the transient one-dimensional flow and solute transport in variably saturated porous media. The program is widely used on farmland irrigation research and it is not suitable for runoff calculation because the boundary condition can't change as the change of water content in the soil. HYrunoff, which is developed by the institute of hydrology and water resources at Tsinghua University, is the modification and improvement of HYDRUS. The mainly developed function is that it is applicable for the runoff estimation.

The series daily rainfall data from 1956 to 2001 in Beijing were collected and the daily runoff of both pervious area and impervious area were calculated using the continuous simulation of HYrunoff. Annual rainfall is listed in the Table 1 column (2). The results of each year runoff of pervious area and impervious area are listed in the Table 1 column (3) and (4).

According to the multi-year average annual rainfall, the runoff coefficient after the development of the Olympic Park can be determined using the following equation. 


$$
\alpha=\frac{R_{1} A_{1}+R_{2} A_{2}}{P A}
$$

Where, $\alpha$ is the runoff coefficient; $R_{1}$ is the impervious area runoff, $\mathrm{mm} ; A_{1}$ is the area of the impervious zone but not including the lake area $\left(196,775 \mathrm{~m}^{2}\right), \mathrm{m}^{2} ; R_{2}$ is the pervious area runoff, $\mathrm{mm}$; $A_{2}$ is the area of pervious zone, $\mathrm{m}^{2} ; P$ is the average annual rainfall, $\mathrm{mm} ; A$ is the total area, $\mathrm{m}^{2}$.

The Table 1 shows the result of the calculation. Ignoring the rainwater utilization measures, the runoff coefficient after the development of the Olympic Park is 0.692.

Table 1 Calculation of the runoff coefficient using the rainfall data from 1956 to 2001

\begin{tabular}{|c|c|c|c|c|}
\hline Year & $\begin{array}{c}\text { Rainfall } \\
(\mathrm{mm})\end{array}$ & $\begin{array}{c}\text { Pervious area runoff } \\
(\mathrm{mm})\end{array}$ & $\begin{array}{c}\text { Impervious area runoff } \\
(\mathrm{mm})\end{array}$ & $\begin{array}{c}\text { Runoff } \\
\text { coefficient }\end{array}$ \\
\hline$(1)$ & $(2)$ & $(3)$ & $(4)$ & $(5)$ \\
\hline 1956 & 1115.70 & 212.42 & 1025.40 & 0.748 \\
\hline 1957 & 486.80 & 26.06 & 409.70 & 0.659 \\
\hline 1958 & 691.90 & 96.39 & 619.00 & 0.718 \\
\hline$\ldots$ & $\ldots$ & $\ldots$ & 201.60 & $\ldots$ \\
\hline 1999 & 269.70 & 0.00 & 304.70 & 0.576 \\
\hline 2000 & 374.70 & 20.89 & 274.20 & 0.638 \\
\hline 2001 & 341.70 & 22.93 & & 0.632 \\
\hline Average & 600.14 & & $\ldots .692$ \\
\hline
\end{tabular}

\section{Relationship between the runoff coefficient and the proportion of impervious area}

The runoff coefficient is affected by many factors such as underlying surface, rainfall quantity, rainfall intensity, rainfall process, the human activities etc. For a specific research site, to estimate the runoff coefficient, the area can be simply classified into the pervious portion and the impervious portion based on its underlying surface condition and landuse types. If the relationship between the runoff coefficient and the proportion of the impervious area can be set-up, the runoff coefficient can be further determined according to the proportion of the impervious area.

Assuming the proportion of impervious area is $\beta=A_{1} / A \times 100 \%$, Equation (2) can be transformed to

$$
\alpha=\frac{R_{1}-R_{2}}{P} \beta+\frac{R_{2}}{P} \text {. }
$$

The average annual rainfall $P$ is a constant. $R_{1}, R_{2}$ refer to the runoff of the impervious area and the previous area respectively and they are unchangeable under the same series of the rainfall data. So, a linear relationship exists between $\alpha$ (the runoff coefficient) and $\beta$ (the proportion of the impervious area). However, this linear relationship should not be obtained from a short series of rainfall data, but from a long series of the rainfall data.

Based on the calculation results of HYrunoff listed in the Table 1, for the Olympic Park, the different runoff coefficients can be calculated for the different proportion of the impervious area, the results are listed in the Table 2 and the data are plotted in Fig. 3.

Table 2 Calculation of the runoff coefficient for different proportion of the impervious area

\begin{tabular}{|c|c|c|c|c|c|c|c|c|c|}
\hline Proportion of impervious area (\%) & 79.05 & 95 & 90 & 85 & 75 & 65 & 50 & 35 & 20 \\
\hline Runoff coefficient & 0.692 & 0.811 & 0.774 & 0.736 & 0.661 & 0.586 & 0.474 & 0.361 & 0.249 \\
\hline
\end{tabular}




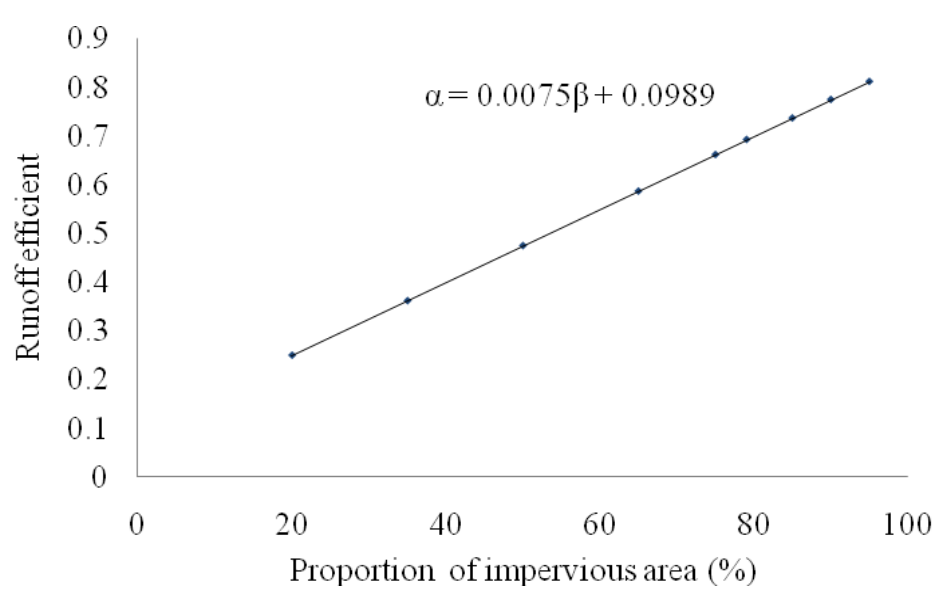

Fig. 3 Relationship of the runoff coefficient and the proportion of the impervious area

The linear relationship between the runoff coefficient and the proportion of impervious area can be summarized as:

$$
\alpha=0.0075 \beta+0.0989 \text {. }
$$

Where, $\alpha$ is the runoff coefficient; $\beta$ is the proportion of the impervious area (\%).

\section{Runoff coefficient before the development}

Referring to the literature, the proportion of the impervious area at the research site before construction was approximately $27.87 \%$. Using the Equation (4), the runoff coefficient of the research site before the development was estimated as 0.308 .

\section{Rainwater utilization potentiality of the Olympic Park}

The total area of the research site is 968 hectares, that is $9.68 \mathrm{~km}^{2}$. The multi-year average annual rainfall is $600 \mathrm{~mm}$. And the runoff coefficients before and after the construction of the Olympic Park are 0.692 and 0.308 respectively. So, based on the definition of RUPUA, the rainwater utilization potentiality of the research site is

$$
W=1000 P\left(\alpha_{1}-\alpha_{2}\right) F=1000 \times 600 \times(0.692-0.308) \times 9.68=2,230,000 \mathrm{~m}^{3}
$$

\section{Runoff and rainwater utilization quantity considering different rainwater utilization measures}

In the designing and the planning of the Beijing Olympic Park, three rainwater utilization measures were considered. The first rainwater utilization measure is to construct the sunken lawns, most lawns of the central zone are sunken lawns instead of the general ones. The sunken lawns were designed to be $5 \sim 10 \mathrm{~cm}$ below the around surface to collect the rainwater and enhance the rainfall infiltration. The second measure is to pave the water permeable bricks, the water permeable brick (EP Brick) is used for parking lot and some of the sidewalk. The third measure is to construct water storage tanks, above-ground and underground water storage tanks are constructed in order to gathering the roof excess rainfall and make the rainwater available for later use. Runoffs of these three rainwater utilization measures are discussed separately as following.

\section{Runoff of the sunken lawn}

A sunken lawn can be used to collect the runoff produced on the lawn, and to increase the infiltration into the soil and therefore reducing the runoff coefficient. Basing on the former research, it is assumed that the depth of the sunken lawn is $100 \mathrm{~mm}$, which can decrease the runoff coefficient effectively and make sure the grass will grow well.

The calculation of the sunken lawn runoff is performed on the basis of the previous pervious area daily runoff data. Supposing that the infiltration rate of the cumulated water is $5 \mathrm{~mm} / \mathrm{d}$, the actually runoff is $R_{\mathrm{i}}=L_{\mathrm{i}}-100$ if the cumulated water depth is greater than $100 \mathrm{~mm}\left(L_{\mathrm{i}}>100 \mathrm{~mm}\right)$. If the cumulated water depth is less than $100 \mathrm{~mm}$, ie. $L_{i} \leq 100 \mathrm{~mm}$, the actually runoff is 0 . Column (3) in Table 3 shows the result of yearly sunken lawn runoff. 


\section{Runoff of the water permeable brick}

Water permeable brick (EP Brick) are composed of recycled glass and ceramic wastes, mixed together with high-molecule compounds in computer-aided temperature controlled procedures. Non-permeable construction materials, such as bitumen and cement, largely used in urban construction, are indirectly destroying the ability for the earth to retain and store water and results in flooded rivers whenever it rains. EP Construction Materials are capable of diffusing water into the earth, not only providing flood assistance but also contributing to temperature control.

The calculation of the water permeable brick runoff is on the basis of the impervious area runoff day by day. It is assumed that the thickness and the effective porosity of water permeable brick are 60 $\mathrm{mm}$ and $10 \%$, and the thickness and the effective porosity of cushion layer are $200 \mathrm{~mm}$ and $25 \%$. So, the depth for storing the rainwater is $56 \mathrm{~mm}$. Supposing that the infiltration rate is $5 \mathrm{~mm} / \mathrm{d}$, the actual runoff is $R_{\mathrm{i}}=L_{\mathrm{i}}-56$ if the cumulated water depth is greater than $56 \mathrm{~mm}$. If the cumulated water depth $L_{i} \leq 56 \mathrm{~mm}$, the actually runoff is 0 . Column (5) in Table 3 shows the result of the runoff for water permeable brick (EP Brick).

Table 3 Calculation of the sunken lawn and EP Brick runoff using the data from 1956 to 2001

\begin{tabular}{|c|c|c|c|c|}
\hline Year & $\begin{array}{c}\text { Pervious area runoff } \\
(\mathrm{mm})\end{array}$ & $\begin{array}{c}\text { Sunken lawn runoff } \\
(\mathrm{mm})\end{array}$ & $\begin{array}{c}\text { Impervious area runoff } \\
(\mathrm{mm})\end{array}$ & $\begin{array}{c}\text { EP Brick runoff } \\
(\mathrm{mm})\end{array}$ \\
\hline$(1)$ & $(2)$ & $(3)$ & 1025.40 & 425.50 \\
\hline 1956 & 212.42 & 18.77 & 409.70 & 37.80 \\
\hline 1957 & 26.06 & 0 & 619.00 & 212.40 \\
\hline 1958 & 96.39 & 0 & $\ldots$ & $\ldots$ \\
\hline$\ldots$ & $\ldots$ & $\ldots$ & 651.50 & 167.60 \\
\hline 1998 & 92.16 & 0 & 201.60 & 0.00 \\
\hline 1999 & 0 & 0 & 304.70 & 21.60 \\
\hline 2000 & 20.89 & 0 & 274.20 & 50.40 \\
\hline 2001 & 22.93 & 0 & & \\
\hline
\end{tabular}

\section{Rainwater utilization quantity of the storage tank}

In the designing of the Beijing Olympic Park, above-ground and underground water storage tanks are made for collecting the roof rainwater from the buildings. The total design capacity of the storage tanks is $37,700 \mathrm{~m}^{3}$ and the roof area connecting to the storage tank is $634,400 \mathrm{~m}^{2}$.

In Beijing, a hydrological year can be divided into the flood season and the non-flood season, the rain is mainly concentrated in the flood season, which starts from the beginning of June and end at the end of September. During this period, the storage tanks may not able to collect all the roof rainwater and therefore there are may be some discarded water. In non-flood season, the storage tanks can collect all the roof rainwater.

During the flood season, the daily calculation model of the storage tank rainwater utilization quantity is as Equation (5).

$$
Q_{1}=\sum_{i=1}^{n} f\left(Q_{I}^{i}+Q_{S}^{i}-Q_{q}\right)
$$

Where, $Q_{1}$ is the utilized rainwater volume during the flood season from the water storage tanks, $\mathrm{m}^{3} ; Q_{I}^{i}$ is the inflow volume of the rainwater on the ith day, $\mathrm{m}^{3} ; Q_{S}^{i}$ is the water volume in the storage tanks at the beginning of the ith day, $\mathrm{m}^{3} ; Q_{q}$ is the daily water quota, $\mathrm{m}^{3} / \mathrm{day} . \mathrm{n}$ is number of days, there are 122 days from June to September; $f\left(Q_{I}^{i}+Q_{S}^{i}-Q_{q}\right)$ is the daily rainwater utilization quantity from the water storage tanks, $\mathrm{m}^{3}$. 
For the daily rainwater utilization quantity from the water storage tanks, referring to Fig. 4, there are three kinds of situation which are considered in the research.

(1) When $Q_{I}^{i}+Q_{S}^{i}-Q_{q}>37700 m^{3}$, at the end of the ith day, the available storage quantity exceeds the storage tank capacity. So, the storage tanks are full and there will be some discarded water.

$$
f\left(Q_{I}^{i}+Q_{S}^{i}-Q_{q}\right)=Q_{q}, \quad Q_{S}^{i}=37700 m^{3} ;
$$

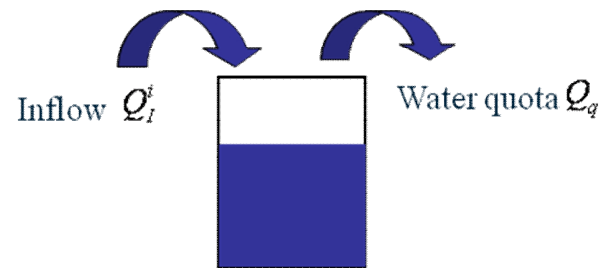

Initial storage quantity $Q_{S}^{i}$

Fig. 4 Sketch of the storage tankLanduse types of the research site

(2) When $0<Q_{I}^{i}+Q_{S}^{i}-Q_{q}<37700 m^{3}$, at the end of the ith day, the available storage quantity is less than the storage tank capacity. So,

$$
f\left(Q_{I}^{i}+Q_{S}^{i}-Q_{q}\right)=Q_{q}, \quad Q_{S}^{i}=Q_{I}^{i}+Q_{S}^{i}-Q_{q} ;
$$

(3) When $Q_{I}^{i}+Q_{S}^{i}-Q_{q} \leq 0$, the sum of the inflow and the initial storage quantity is less than the daily water quota. At the end of the day, the storage tank is empty.

$$
f\left(Q_{I}^{i}+Q_{S}^{i}-Q_{q}\right)=Q_{I}^{i}+Q_{S}^{i}, \quad Q_{S}^{i}=0 .
$$

During the non-flood season, the storage tanks can collect all the roof rainwater. So, the storage tank rainwater utilization quantity is

$$
Q_{2}=\sum_{i=1}^{n} R_{i}
$$

Where, $Q_{2}$ is the storage tank rainwater utilization quantity during the non-flood season, $\mathrm{m}^{3} ; R_{\mathrm{i}}$ is the daily quantity of the collected rainwater, $\mathrm{m}^{3}$.

Therefore, the total rainwater utilization of the storage tanks in a year is

$$
Q=Q_{1}+Q_{2} \text {. }
$$

Supposing that the daily water quota is $3,000 \mathrm{~m}^{3} /$ day, the annual rainwater utilization of storage tank is $239,000 \mathrm{~m}^{3}$, the annual discarded water is $95,000 \mathrm{~m}^{3}$ and the proportion of water abandoning is $28.5 \%$.

The proportion of water abandoning varies along the change of the storage tank capacity, referring to Fig. 5. The proportion of water abandoning decreases when the storage tank capacity increases. When the storage tank capacity is small, the proportion of water abandoning drops quickly with the increase of the storage tank capacity. When the storage tank capacity is large, the proportion of water abandoning decreases much more slowly with the

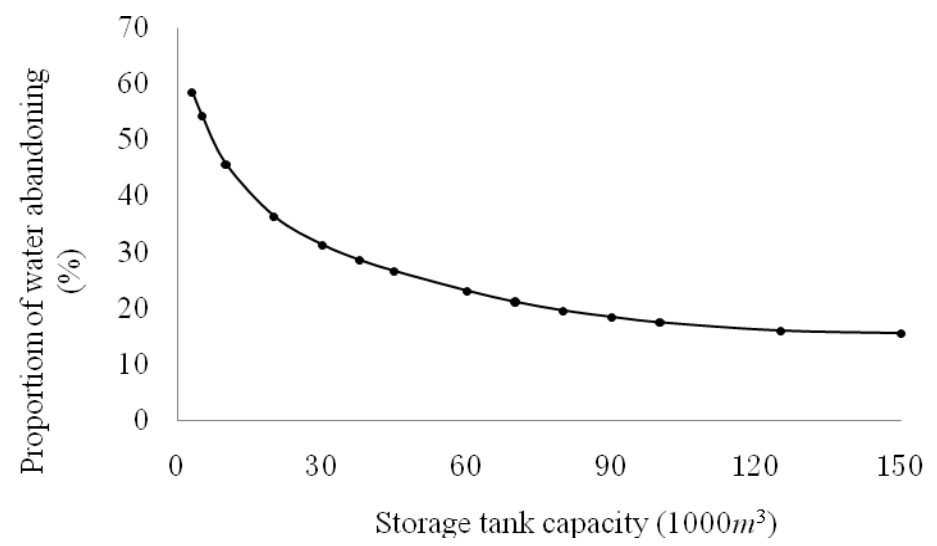

Fig. 5 Relation between proportion of water abandoning and storage tank capacity increase of the storage tank capacity. When it comes to the actual design of the storage tank, the capacity would be relatively optimal considering the factors of economy and technology. 


\section{Comparison of the different rainwater utilization measures}

According to previous discussion, the rainwater utilization potentiality of the Beijing Olympic Park is $2,230,000 \mathrm{~m}^{3}$. In order to compare the rainwater utilization effect of different rainwater utilization measures, four cases are further discussed here.

(1) Case 1: only sunken lawn will be constructed. When $50 \%$ of the total designed lawn will be sunken, the rainwater utilization quantity is $54,000 \mathrm{~m}^{3}$, accounting for $2.4 \%$ of the rainwater utilization potentiality.

(2) Case 2: only water permeable brick will be constructed. The sidewalk, parking lots and part of the square use water impermeable brick to increase infiltration. From the landuse design of the Olympic Park, the total square and road area is 3,209,000 $\mathrm{m}^{2}$. Supposing $10 \%$ of the total area is paved with the water permeable brick, the rainwater utilization quantity is $128,000 \mathrm{~m}^{3}$, accounting for $5.7 \%$ of the rainwater utilization potentiality.

(3) Case 3: only water storage tanks will be constructed. Referring to 4.3, the total design capacity of the water storage tanks is $37,700 \mathrm{~m}^{3}$, the roof area of the buildings is $634,400 \mathrm{~m}^{2}$ and the daily water quota is $3,000 \mathrm{~m}^{3} /$ day. The rainwater utilization quantity of the storage tanks is $239,000 \mathrm{~m}^{3}$, accounting for $10.7 \%$ of the rainwater utilization potentiality.

(4) Case 4: combining the sunken lawn, water permeable brick and the storage tanks. The rainwater utilization quantity of Case 4 is $414,000 \mathrm{~m}^{3}$, accounting for $18.6 \%$ of the rainwater utilization potentiality.

Table 4 Comparison of different rainwater utilization measures

\begin{tabular}{|l|c|c|c|}
\hline \multicolumn{1}{|c|}{ Case } & $\begin{array}{c}\text { Total rainwater } \\
\text { utilization potentiality } \\
\left(\times 1000 \mathrm{~m}^{3}\right)\end{array}$ & $\begin{array}{c}\text { Rainwater utilization } \\
\text { quantity } \\
\left(\times 1000 \mathrm{~m}^{3}\right)\end{array}$ & $\begin{array}{c}\text { Percentage } \\
(\%)\end{array}$ \\
\hline Only sunken lawn & & 54 & 2.4 \\
\hline Only water permeable brick & & 128 & 5.7 \\
\hline Only storage tank & \multirow{2}{*}{2,230} & 239 & 10.7 \\
\hline $\begin{array}{l}\text { Combining sunken lawn, water } \\
\text { permeable brick and storage tanks }\end{array}$ & & 414 & 18.6 \\
\hline
\end{tabular}

\section{Conclusions}

1) Under the definition of RUPUA, the rainwater utilization potentiality at the research site is $2,230,000 \mathrm{~m}^{3}$.

2) Water storage tanks were designed to collect the rainwater from the building roofs, if the daily water quota is $3,000 \mathrm{~m}^{3} /$ day and the volume of the storage tanks is $37,700 \mathrm{~m}^{3}$, the annual rainwater utilization by the storage tanks is $239,000 \mathrm{~m}^{3}$, the annual discarded water is $95,000 \mathrm{~m}^{3}$. The proportion of water abandoning is $28.5 \%$. The proportion of water abandoning decreases when the storage tank capacity increases.

3) For the research site, if $50 \%$ of the total lawn is sunken, $10 \%$ of the square and road area is paved with the water permeable brick, the total design capacity of the storage tanks is $37,700 \mathrm{~m}^{3}$, and the daily water quota is $3,000 \mathrm{~m}^{3} / \mathrm{day}$, the annual rainwater utilization quantity is $414,000 \mathrm{~m}^{3}$.

\section{Acknowledgements}

This work was financially supported by the Jiangsu Provincial Water Science and Technology Project (No.2017022\& No.2017038), National Science Foundation for Young Scientists of China (Grant No.31400617). 


\section{References}

[1] China Water Resources Assessment Guide. SL/T238-1999

[2] YANG Zhongshan. Impact study of hydrological characteristics by urbanizing. Annual report. Beijing, Beijing hydrological station. 2008.12

[3] SUN Li, et.al. Discussion of rainwater utilization measures in the cities. Enterprise Science and Technology and Development, 2007.14: 179 181

[4] ZHANG Sicong, et.al. Beijing rainwater utilization. Beijing Water Resources, 2003.4: 20 22

[5] CHEN Chuang. Study on the simulated calculation of rainwater utilization and flood control in urban area. Master thesis, Beijing, Tsinghua University. 2008.6 